\title{
Bartholin Gland Endometriosis
}

\author{
${ }^{1}$ Nutan Jain, ${ }^{2}$ Sonam Singh
}

\begin{abstract}
Endometriosis is a commonly encountered benign gynecological disease, involving extrauterine growth of both endometrial glands and elements of endometrial stroma. Like ectopic endometrial tissue, these ectopic foci are susceptive to cyclic hormonal changes. A case of endometriosis infiltrating the Bartholin gland is presented. The initial diagnosis was a Bartholin gland cyst. The clinical diagnosis was made during the operation when chocolate-colored material poured into operation field, and histopathologic examination confirmed the presence of endometriosis. Bartholin gland endometriosis should be kept in mind when women of reproductive age have a diagnosis of Bartholin cyst. It is a rare case and only few cases are reported in the literature.
\end{abstract}

Keywords: Bartholin cyst, Bartholin gland, Endometriosis, Total laparoscopic hysterectomy in Bartholin cyst.

How to cite this article: Jain N, Singh S. Bartholin Gland Endometriosis. Int J Gynecol Endsc 2017;1(1):32-34.

Source of support: Nil

Conflict of interest: None

\section{INTRODUCTION}

Endometriosis is defined as implantation and growth of endometrial tissue on sites other than the endometrium. ${ }^{1}$ Endometriosis is a commonly encountered benign gynecological disease, involving extrauterine growth of both endometrial glands and elements of endometrial stroma. Like ectopic endometrial tissue, these ectopic foci are susceptive to cyclic hormonal changes. This progressive inflammatory disease is mostly encountered in the latter half of the reproductive era and is reported with a prevalence of 7 to $10 \%$ in the general population. ${ }^{2-4}$

The most frequently involved locations are defined as the ovaries $(30 \%)$, uterosacral and cardinal ligaments (18-24\%), the fallopian tubes $(20 \%)$, pelvic peritoneum, and gastrointestinal system. ${ }^{5,6}$ However, there are various reports on the disease in extrapelvic, more eccentric locations, such as the inguinal canal, thoracic cavity, the nasal

\footnotetext{
${ }^{1}$ Director, ${ }^{2}$ Clinical Research Fellow

1,2Department of Gynaecology and Obstetrics, Vardhman Trauma \& Laparoscopy Centre, Muzaffarnagar, Uttar Pradesh India

Corresponding Author: Nutan Jain, Director, Department of Gynaecology and Obstetrics, Vardhman Trauma \& Laparoscopy Centre, Muzaffarnagar, Uttar Pradesh, India Phone: +911312623084, e-mail: jainnutan@gmail.com
}

epithelium, and abdominal wall. ${ }^{7-9}$ The cysts of Bartholin gland are one of the most common lesions of vulva, but endometriosis of the Bartholin gland is extremely rare. Endometriosis may occur primarily in the Bartholin gland and secondary in episiotomy scars, postoperative perineal incision sites, and vulvar lacerations. ${ }^{10-13}$ Vulvar endometriosis is considerably rare and is, therefore, generally overlooked. The incidence of vulvar endometriosis in patients treated for pelvic endometriosis has been reported to be $0.37 \%{ }^{14,15}$ The dark brown content of the cyst usually predicts endometriosis, but the exact diagnosis can only be made by histopathologic examination.

The aim of this case report is to document a Bartholin gland endometriosis. The ducts of the Bartholin glands open to the vaginal orifice and mucus secreted by the Bartholin glands causes lubrication during intercourse. The reported rate of vulvar endometriosis is considered to be lower than expected and most are detected as asymptomatic vulvar masses; however, the most predominant symptom is cyclic vulvar swelling, vulvodynia, and dyspareunia. The following case describes a patient with vulvar endometriosis mimicking a Bartholin cyst, successfully treated with local excision.

\section{CASE REPORT}

A 40-year-old woman, para 2, live 2, and abortion 1 with previous two normal vaginal deliveries, was admitted to Vardhman Laparoscopic Centre, a tertiary referral center for laparoscopy and hysteroscopy with complaints of menorrhagia and dysmenorrhea. The patient had previous two normal vaginal deliveries and the last delivery was 18 years back. Also, there was history of lapcholecystectomy in 2008. She had no history of any other disease. The vital signs of the patient were normal. On gynecological examination, there was a $3 \times 3 \mathrm{~cm}$ cystic lesion on the right Bartholin gland (Fig. 1), and uterus was palpated as bulky, fixed, retroverted, very tender, nodular, thickened uterosacral ligament with deep probe tenderness. Complete blood count and basic biochemical tests were in normal limits. Urinalysis and cervical and urinary cultures were negative. Transvaginal ultrasonographic examination revealed globular uterus with two small adenomyoma and right endometriotic cyst of size $4.2 \times 3.9 \mathrm{~cm}$.

The patient was taken for total laparoscopic hysterectomy (TLH) for deep infiltrating endometriosis. After $\mathrm{TLH}$, the cystic lesion was evaluated as Bartholin cyst 


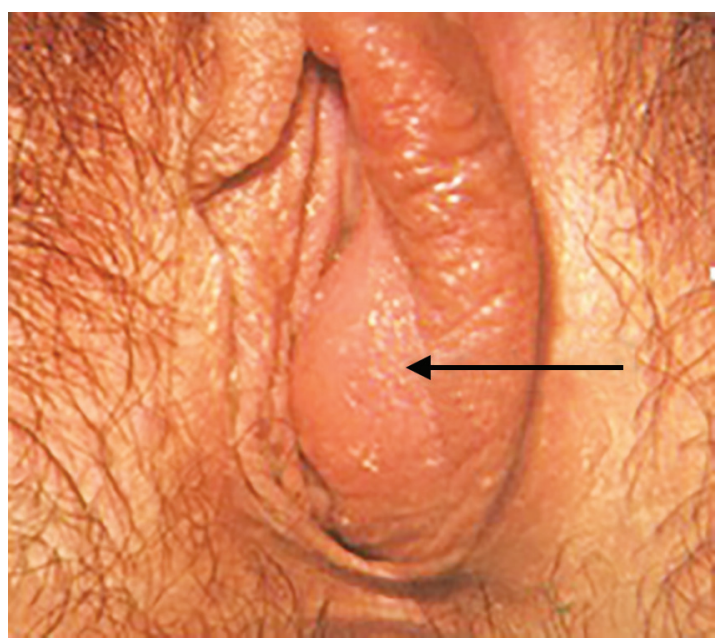

Fig. 1: Right Bartholin cyst

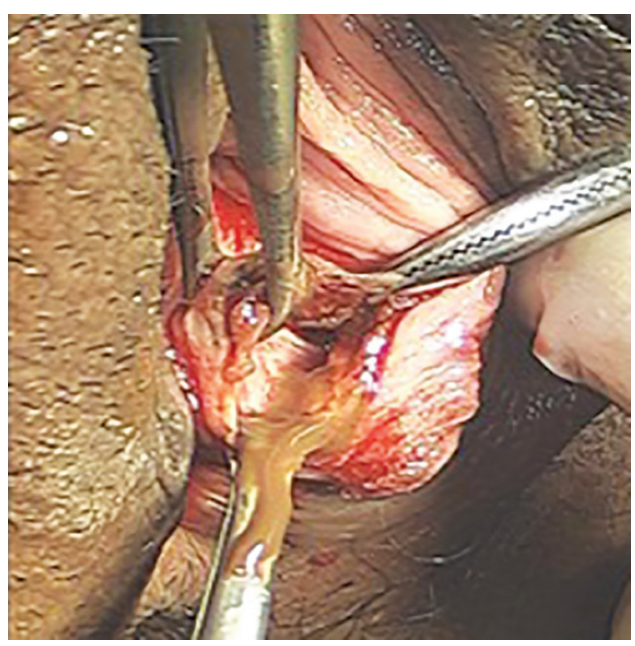

Fig. 2: Chocolate material draining from cyst
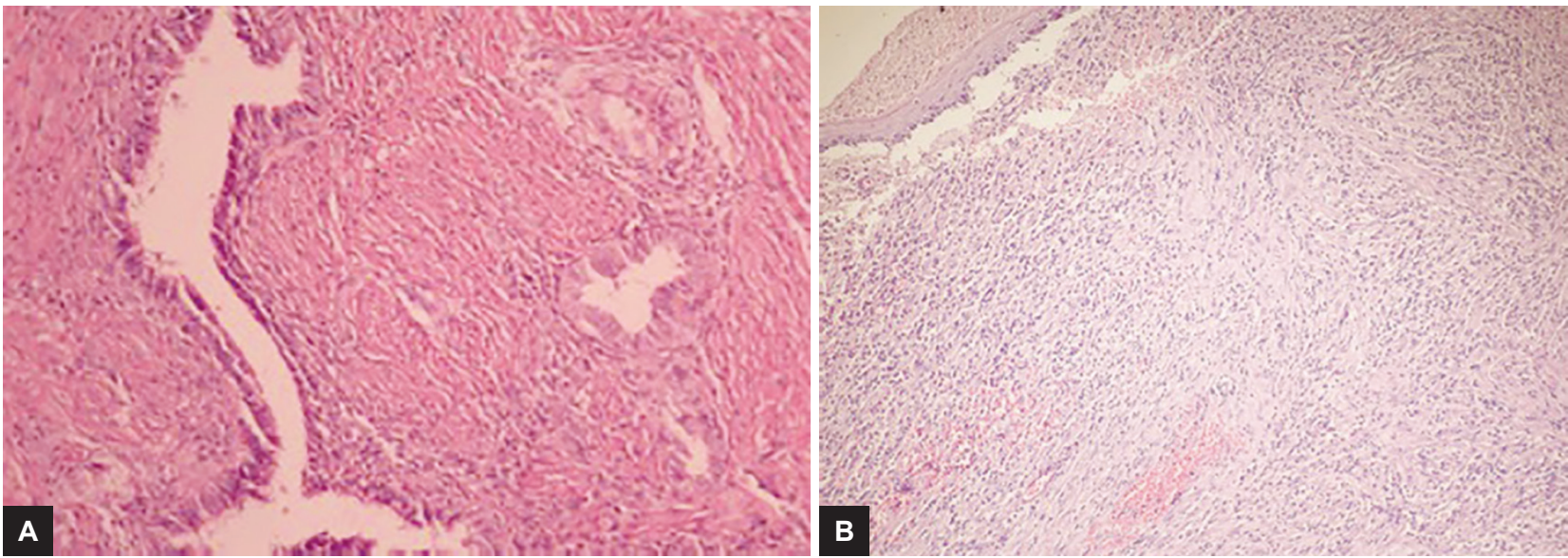

Figs $3 \mathrm{~A}$ and $\mathrm{B}$ : (A) Endometrial glands and stroma along with hemosiderin-laden macrophages; and

(B) Hemosiderin-loaded macrophages in the squamous epithelium-lined Bartholin gland

and excision of the cyst was planned. Informed consent covering permission for documentation of the case was taken from the patient before the operation. The patient was prepared for the operation and draped in lithotomy position. Dissection of the labium majus above the mass revealed a $3 \mathrm{~cm}$ cystic lesion that was excised by giving vertical incision and chocolate material was expelled (Fig. 2). This was totally unexpected and rather than pus or mucus, we had chocolate draining out. The cyst lining was carefully excised and sent for histopathology, which further reconfirmed the diagnosis of endometriosis (Figs 3A and B). Uterus and rectovaginal nodule histopathology showed adenomyosis. The patient was discharged from the hospital next day and follow-up was uneventful.

\section{DISCUSSION}

Endometriosis is a pathological condition characterized by the presence of endometrial tissue outside the endometrium. Evidence suggests that ectopic endometrium usually results from transplantation of viable endometrial tissue, which is shed in a retrograde manner through the fallopian tube at the time of menstruation (Sampson's theory). ${ }^{16}$ No factors that may favor intraperitoneal growth of viable endometrium have been identified, although impaired cellular immunity as well as increased exposure to retrograde menstruation may play a role. Hematogenous and lymphatic spread, direct implantation, and transformation of totipotential mesothelial cells (Meyer's theory $)^{17}$ undoubtedly contribute a minority of cases to the overall incidence. The origin of endometriosis in extraabdominal pelvic sites is not fully understood. Vascular dissemination or direct implantation through the openings of the ducts of Bartholin glands may explain the formation of endometriosis in the Bartholin glands. Endometriosis of the Bartholin gland is extremely rare. Isolated endometriosis in a Bartholin gland was first reported by Matseoane et al. ${ }^{18}$

Direct extension of endometriosis along the round ligament from preexisting pelvic endometriosis can explain endometriosis of the labium majus. An isolated focus of endometriosis in the Bartholin gland can, theoretically, 
be the result of coelomic metaplasia, lymphatic and/ or vascular spread. Hormonal stimulation can result in the growth of endometrial fragments that have reached the Bartholin gland via menstrual discharge. ${ }^{19}$ The etiopathogenetic mechanism of Bartholin gland endometriosis would be related to iatrogenic transplantation of endometrium during delivery or gynecological surgery. Vulvar endometriosis in other previous cases was probably the result of implantation of endometrial tissue in open accidental vulvar trauma; during sexual intercourse or during endometrial biopsy performed. Buda et $\mathrm{al}^{20}$ clinically confirmed this iatrogenic pathogenesis after laparoscopic surgery. On the contrary, our patient did not have a history of any gynecological invasive process. She gave birth vaginally without an episiotomy.

Although rare, Bartholin gland endometriosis should always be borne in mind when women of reproductive age have a presumptive diagnosis of Bartholin cyst, especially if it is associated with menstrual variability in size and pain. In fact, there is no real way to prevent this rare location of endometriosis. ${ }^{21}$

\section{REFERENCES}

1. Giudice LC, Kao LC. Endometriosis. Lancet 2004 Nov 13-19; 364(9447):1789-1799.

2. Cramer DW, Missmer SA. The epidemiology of endometriosis. Ann N Y Acad Sci 2002 Mar;955:11-22.

3. Viganò P, Parazzini F, Somigliana E, Vercellini P. Endometriosis: epidemiology and aetiological factors. Best Pract Res Clin Obstet Gynaecol 2004 Apr;18(2):177-200.

4. Wheeler JM. Epidemiology of endometriosis-associated infertility. J Reprod Med 1989 Jan;34(1):41-46.

5. Jenkins S, Olive DL, Haney AF. Endometriosis: pathogenetic implications of the anatomic distribution. Obstet Gynecol 1986 Mar;67(3):335-338.

6. Hassa H, Tanir HM, Uray M. Symptom distribution among infertile and fertile endometriosis cases with different stages and localisations. Eur J Obstet Gynecol Reprod Biol 2005 Mar 1; 119(1):82-86.

7. Kim DH, Kim MJ, Kim ML, Park JT, Lee JH. Inguinal endometriosis in a patient without a previous history of gynecologic surgery. Obstet Gynecol Sci 2014 Mar;57(2):172-175.
8. Mignemi G, Facchini C, Raimondo D, Montanari G, Ferrini G, Seracchioli R. A case report of nasal endometriosis in a patient affected by Behcet's disease. J Minim Invasive Gynecol 2012 Jul-Aug;19(4):514-516.

9. Machairiotis N, Stylianaki A, Dryllis G, Zarogoulidis P, Kouroutou P, Tsiamis N, Katsikogiannis N, Sarika E, Courcoutsakis N, Tsiouda T, et al. Extrapelvic endometriosis: a rare entity or an under diagnosed condition? Diagn Pathol 2013 Dec 2;8:194.

10. Aydin Y, Atis A, Polat N. Bilateral endometrioma of Bartholin glands accompanying ovarian endometrioma. J Obstet Gynaecol 2011;31(2):187-189.

11. Tornqvist B. Endometriosis in vaginal, vulvar and perineal scars. Acta Obstet Gynecol Scand 1949;28(3-4):485-489.

12. Jain D. Perineal scar endometriosis: a comparison of two cases. BMJ Case Rep 2013 Jul 29;2013. pii: bcr2013010051.

13. Strube FA, Niazi M, Lazarou G. Enlarging perineal endometrioma developing after colpoperineorrhaphy. Int Urogynecol J 2011 Oct;22(10):1325-1327.

14. Zhu L, Lang J, Wang H, Liu Z, Sun D, Leng J, Zhou H, Cui Q, Wong F. Presentation and management of perineal endometriosis. Int J Gynaecol Obstet 2009 Jun;105(3):230-232.

15. Zhu L, Chen N, Lang J. Diagnosis and treatment of perineal endometriosis. In: Chaudhury K, Chakravarty B, editors. Endometriosis - basic concepts and current research trends. InTech; 2012.

16. Sampson JA. The development of the implantation theory for the origin of peritoneal endometriosis. Am J Obstet Gynecol 1940;40:549.

17. Meyer R. Über den stand der adenomyositis und adenomyome im allgemeinen und insbesondere über adenomyositis serosepithelialis und adenomyometritis sarcomatosa. Zbl Gynak 1919;43:745.

18. Matseoane $S$, Harris T, Moscowitz E. Isolated endometriosis in a Bartholin gland. N Y State J Med 1987 Oct;87(10):575-576.

19. Gocmen A, Inaloz HS, Sari I, Inaloz SS. Endometriosis in the Bartholin gland. Eur J Obstet Gynecol Reprod Biol 2004 May 10;114(1):110-111.

20. Buda A, Ferrari L, Marra C, Passoni P, Perego P, Milani R. Vulvar endometriosis in surgical scar after excision of the Bartholin gland: report of a case. Arch Gynecol Obstet 2008 Mar;277(3):255-256.

21. Singh KK, Lessells AM, Adam DJ, Jordan C, Miles WF, Macintyre IM, Greig JD. Presentation of endometriosis to general surgeons: a 10-year experience. Br J Surg 1995 Oct;82(10):1349-1351. 